\title{
Factors affecting current khat chewing among male adults 15-59 years in Ethiopia, 2016: a multi-level analysis from Ethiopian Demographic Health Survey
}

Temesgen Yihunie Akalu ${ }^{1}$, Adhanom Gebreegziabher Baraki ${ }^{*}$, Haileab Fekadu Wolde ${ }^{1}$, Ayenew Molla Lakew ${ }^{1}$ and Kedir Abdela Gonete ${ }^{2}$

\begin{abstract}
Background: Regular khat chewing causes gingivitis, tooth loss, gastric disorders, cardiac complications, male impotence, sleeplessness, and several mental health problems. Based on the Ethiopian Demographic and Health Survey (EDHS) 2016, 12\% of women and 27\% of men have reported having ever chewed khat. Even though khat addiction is a major public health problem, studies that consider both individual level and community level factors are limited. Therefore, this study aimed to determine the prevalence and factors affecting current khat chewing among male adults in Ethiopia.
\end{abstract}

Methods: Data from EDHS, a community-based cross-sectional study conducted from January 18, 2016, to June 27, 2016, was used. A multistage stratified cluster sampling technique was used to select participants. Both descriptive and analytical statistics were done. Bi-variable and multivariable multilevel logistic regression analyses were performed to determine factors affecting current khat chewing. Adjusted Odds ratio (AOR) with 95\% Confidence Interval (Cl) for variables with $P$-value $<0.05$ was used as a measure of association.

Result: A total of 12,595 male adults were included. The prevalence of current khat chewing was 23.61\% (95\% Cl: 22.87, 24.36). Age 20-24 years; $(A O R=2.68,95 \% \mathrm{Cl}: 2.02,3.56)$, being uneducated $(A O R=1.62,95 \% \mathrm{Cl}: 1.10,2.39)$, professional/technical/managerial job ( $A O R=3.59,95 \% \mathrm{Cl}: 2.18,5.91)$, Muslim religion ( $\mathrm{AOR}=18.30,95 \% \mathrm{Cl}: 13.54$, 24.74), poorest wealth index ( $A O R=0.67,95 \% \mathrm{Cl}: 0.51,0.89$ ), being divorced ( $A O R=0.38,95 \% \mathrm{Cl}: 0.21,0.69$ ), history of alcohol drinking in the last 30 days $(A O R=2.15,95 \% \mathrm{Cl}: 1.69,2.73)$, and history of cigarette smoking in the last 30 days ( $A O R=14.92,95 \% \mathrm{Cl}: 10.88,20.47)$, and Amhara region ( $A O R=0.07,95 \% \mathrm{Cl}: 0.04,0.14$ ) were significantly associated with khat chewing.

Conclusion: Khat chewing remains high in Ethiopia with certain regional variations. The uneducated, older age, Alcohol and cigarette users, Muslims, and professional workers were at higher risk of khat chewing whereas the poorest wealth index and being divorced reduced its risk. Policymakers should consider a multi-faceted policy approach that accounts for regional variation and the identified risk factors to alleviate the problem.

Keywords: Khat, Ethiopia, EDHS, Multilevel

\footnotetext{
* Correspondence: adsh04@gmail.com

${ }^{1}$ Department of Epidemiology and Biostatistics, Institute of Public Health,

College of Medicine and Health Sciences, University of Gondar, Gondar,

Ethiopia

Full list of author information is available at the end of the article
}

(c) The Author(s). 2020 Open Access This article is distributed under the terms of the Creative Commons Attribution 4.0 International License (http://creativecommons.org/licenses/by/4.0/), which permits unrestricted use, distribution, and reproduction in any medium, provided you give appropriate credit to the original author(s) and the source, provide a link to the Creative Commons license, and indicate if changes were made. The Creative Commons Public Domain Dedication waiver (http://creativecommons.org/publicdomain/zero/1.0/) applies to the data made available in this article, unless otherwise stated. 


\section{Background}

Khat, native to Ethiopia, and the southern Arabian Peninsula is an evergreen shrub cultivated as a bush or small tree [1]. Its young buds and tender leaves (the main utilized part) contain amphetamine-like psychoactive substances, which produce euphoria and stimulation [2]. People chew khat for a variety of reasons, these include entertainment, as part of social events, to spend time, as a culture and some also use it to stay active when studying [3].

Regular khat chewing: causes gingivitis, tooth loss, gastric disorders, cardiac complications, male impotence, sleeplessness, and several mental health problems [4-7]. A study from Ethiopia suggests that khat chewing resulted in poor lung function and oxygen saturation [8], risky sexual behavior [9, 10], and psychosis [11]. In addition, concurrent use of khat with alcohol and cigarette smoking was highly associated with sleep disturbance [12].

High prevalence of khat chewing has been recorded in Yemen and the Jazan region of Saudi Arabia. According to global synthetic drug assessment in 2014, the prevalence of khat chewing among people aged 16 and above in Yemen was 52\% [13]. In the last several years, khat has been increasingly transported from East Africa including (Ethiopia, Kenya, and Uganda) and the Arabian Peninsula (Yemen) to other regions [14]. A large amount of khat is smuggled from Ethiopia and Kenya to the United Kingdom and the Netherlands by plane, where until recently it has not been under national control in either of the countries [15].

Based on the Ethiopian Demographic and Health Survey (EDHS) 2016, 12\% of women and 27\% of men report having ever chewed khat [16]. Khat consumption increases with age and peaks at age 30-34 among both women (15\%) and men (34\%) [17].

The major predisposing factors for khat chewing include; family member who had history of khat chewing $[18,19]$, need of concentration and relaxation [13, 20], smoking cigarette, alcohol drinking [6, 21], religious practice [13, 22], economical status [5], peer pressure [5, 19, 23], place of residence [19], and increased workload [22].

Globally, in different countries khat and its consumption has been regulated by the Government [24]. In Ethiopia, especially in the Amhara region, the regional government imposed policy and increased taxation. But the problem remains high and evidence that shows the determinants of khat chewing especially that entertain both individual level and community level factors are limited. Multilevel models can be used to draw individual-level inferences, but inferences can also be made regarding group-to-group variation, including whether it exists in the data, and the extent to which it is accounted for by group and individual-level characteristics [25]. Therefore, this study was aimed to assess the predisposing factors of khat chewing among male adults in Ethiopia.

\section{Methods \\ Study design and setting}

Data from EDHS 2016 was used. EDHS 2016 is a community-based cross-sectional study conducted from January 18, 2016, to June 27, 2016. Ethiopia is situated in the Horn of Africa between 3 and 15 degrees north latitude and 33 and 48 degrees east longitude. Administratively Ethiopia has nine regional states. Namely: Tigray, Afar, Amhara, Oromia, Somali, BenishangulGumuz, Southern Nations Nationalities and peoples Region (SNNPR), Gambella, and Harari. In addition, it has two city administrations, Addis Ababa and Dire-Dawa. More than $82 \%$ of the country's total population lives in the regional states of Amhara, Oromia, and SNNPR [11].

\section{Population, sample size, and sampling technique}

All men from 15 to 59 years in Ethiopia were the source population. Whereas, all men age $15-59$ years in the selected enumeration areas (EAs) were the study population. All men age 15-59 who were the members of the selected households and those who spent the night before the survey in the selected households were included in the study.

The 2016 EDHS used a two-stage stratified cluster sampling technique with regions and residence as strata were used. Primarily, all nine regions were stratified into urban and rural clusters. A total of 654 EAs (202 urban and 443 rural clusters) were selected proportional to EA size. In the second stage of selection, a fixed number of 28 households per cluster were selected from the newly updated listing of households. Altogether, 16,650 households and 12,688 men aged 15-59years were interviewed in the survey.

\section{Study variables}

Current khat chewing status, the outcome variable in this study was defined khat chewing within 30 days prior to the data collection period. The independent variables were grossly classified into socio-demographic and economic factors: age, religion, marital status, educational status, place of residence, region, and behavioral factors: alcohol drinking and smoking, and source of information: reading news-paper, reading magazines, and watching television.

Wealth ranking was grossly categorized into 5 major quintiles based on household assets as lowest (poorest), second (poorer), middle (middle), fourth (richer), and highest (richest). Substance use: was defined as the use 
of one or more of the substance like khat, Alcohol, using any type of tobacco (shisha or Gaya).

\section{Data collection tool and procedure}

The data was taken from EDHS which is collected by trained data collectors using standardized, structured, and pre-tested questionnaires. The questionnaire, based on the DHS Program's standard Demographic and Health Survey questionnaires, were adapted to reflect the population and health issues relevant to Ethiopia. The input was solicited from various stakeholders representing government ministries and agencies, nongovernmental organizations, and international donors. After all, questionnaires were finalized in English, they were translated into local languages. Raw data collected from all part of the country on Men whose age was between 15 and 59 were extracted for the analysis.

\section{Data processing and analysis}

STATA version 14 was used for data analysis. Both descriptive and analytical analysis was done and presented using tables and texts. Bi-variable and multivariable multi-level logistic regressions were performed to determine the existing association among individual and community factors. Initially, a bi-variable analysis was performed and variables with a $p$-value of less than 0.2 were used for further analysis in the multivariable multilevel logistic regression. At the same time, Crude Odds Ratio (COR) and Adjusted Odds Ratio (AOR) with their corresponding confidence intervals $(\mathrm{CI})$ were determined for the bi-variate and multi-variable analysis, respectively. The presence or absence of multi-collinearity was checked using the Variance Inflation Factor (VIF). Finally, $p$-value $<0.05$ was used to declare the significance of association in the multi-variable model. The need for multi-level multivariable analysis which considers community-level factors was tested using the intra-class correlation coefficient (ICC) and models were compared using the deviance tests. The model with the lowest deviance was selected as the best-fitted model. In addition, sensitivity and specificity tests were checked. The presence and absence of univariate and multivariate outliers were checked.

\section{Result}

\section{Baseline characteristics of study participants}

A total of 12,595 participants were included in the study. The mean age of the respondents was $30.7(\mathrm{SD}=11.5)$. One-fifths, $2572(20.4 \%)$ of participants were in the age of 15-19 years. The majority of the participants, 10,099 $(80.2 \%)$ were from rural and $5876(46.7 \%)$ had primary education. More than half, 6968 (55.3\%), of participants, were married (Table 1).
Table 1 Socio-demographic and behavioral factors of adult men 15-59 years in Ethiopia

\begin{tabular}{|c|c|c|}
\hline Variable & Frequency & Percentage \\
\hline \multicolumn{3}{|l|}{ Age in 5 year groups } \\
\hline $15-19$ & 2572 & 20.4 \\
\hline $20-24$ & 1880 & 14.9 \\
\hline $25-29$ & 1975 & 15.7 \\
\hline $30-34$ & 1614 & 12.8 \\
\hline $35-39$ & 1371 & 10.9 \\
\hline $40-44$ & 1188 & 9.4 \\
\hline $45-49$ & 933 & 6.4 \\
\hline $50-54$ & 575 & 4.6 \\
\hline $55-59$ & 487 & 3.9 \\
\hline \multicolumn{3}{|l|}{ Residence } \\
\hline Urban & 2496 & 19.8 \\
\hline Rural & 10,099 & 80.2 \\
\hline \multicolumn{3}{|l|}{ Usual resident or visitor } \\
\hline Usual resident & 12,316 & 97.78 \\
\hline Visitor & 279 & 2.22 \\
\hline \multicolumn{3}{|l|}{ Region } \\
\hline Tigray & 795 & 6.3 \\
\hline Afar & 82 & 0.65 \\
\hline Amhara & 3206 & 25.5 \\
\hline Oromia & 4714 & 37.43 \\
\hline Somali & 326 & 2.6 \\
\hline Benishangul & 123 & 0.98 \\
\hline SNNPR & 2586 & 20.5 \\
\hline Gambella & 37 & 0.29 \\
\hline Harari & 31 & 0.25 \\
\hline Dire-Dawa & 72 & 0.57 \\
\hline Addis Ababa & 621 & 4.9 \\
\hline \multicolumn{3}{|l|}{ Educational level } \\
\hline No education & 3773 & 29.96 \\
\hline Primary education & 5876 & 46.7 \\
\hline Secondary education & 1846 & 14.7 \\
\hline Higher education & 1099 & 8.7 \\
\hline \multicolumn{3}{|l|}{ Occupation } \\
\hline Not working & 944 & 9.5 \\
\hline Professional/technical/managerial & 630 & 5 \\
\hline Clerical & 97 & 0.8 \\
\hline Sales & 677 & 5.4 \\
\hline Agriculture - employee & 8336 & 66.2 \\
\hline Services & 210 & 1.7 \\
\hline Skilled manual & 824 & 6.5 \\
\hline Unskilled manual & 279 & 2.2 \\
\hline Others & 598 & 4.8 \\
\hline
\end{tabular}


Table 1 Socio-demographic and behavioral factors of adult men 15-59 years in Ethiopia (Continued)

\begin{tabular}{|c|c|c|}
\hline Variable & Frequency & Percentage \\
\hline \multicolumn{3}{|l|}{ Religion } \\
\hline Orthodox & 5677 & 45.1 \\
\hline Catholic & 90 & 0.7 \\
\hline Protestant & 2745 & 21.8 \\
\hline Muslin & 3916 & 31.1 \\
\hline Traditional + other & 166 & 1.3 \\
\hline \multicolumn{3}{|l|}{ Sex of household head } \\
\hline Male & 11,034 & 87.6 \\
\hline Female & 1561 & 12.4 \\
\hline \multicolumn{3}{|l|}{ Wealth Index } \\
\hline Poorest & 1979 & 15.7 \\
\hline Poorer & 2294 & 18.2 \\
\hline Middle & 2427 & 19.3 \\
\hline Richer & 2712 & 21.5 \\
\hline Richest & 3183 & 25.3 \\
\hline \multicolumn{3}{|l|}{ Current marital status } \\
\hline Never in union & 4890 & 38.8 \\
\hline Married & 6968 & 55.3 \\
\hline Living with partner & 421 & 3.3 \\
\hline Widowed & 44 & 0.4 \\
\hline Divorced & 226 & 1.8 \\
\hline No longer living together/separated & 46 & 0.4 \\
\hline \multicolumn{3}{|l|}{ Media Exposure } \\
\hline Yes & 8154 & 64.7 \\
\hline No & 4441 & 35.3 \\
\hline \multicolumn{3}{|l|}{ Alcohol drinking in the last 30 days } \\
\hline Yes & 5428 & 43.1 \\
\hline No & 7167 & 56.9 \\
\hline \multicolumn{3}{|l|}{ Smoking cigarette in the last 30 days } \\
\hline Yes & 655 & 5.2 \\
\hline No & 11,940 & 94.8 \\
\hline
\end{tabular}

\section{Prevalence of current khat chewing}

A total number of 2974 participants chewed khat in the last 30 days prior to the survey. This makes the prevalence of current khat chewing 23.61\% (95\% CI: 22.87, 24.36).

\section{The multilevel mixed-effects binary logistic regression model}

The need for the multilevel model was confirmed by ICC of $66 \%$ with $95 \%$ CI $(61.8,70 \%)$. We have also compared the four models (Null model, Individual-level, community level and a model with both individual and community-level factors) and we have found the last model with the lowest deviance to be the best-fitted model (Table 2).

\section{Factors affecting current khat chewing among male adults in Ethiopia}

In the bi-variable multilevel logistic regression analysis; age, sex of household head, residence, educational status, occupation, religion, wealth Index, current marital status, alcohol drinking history in the last 30 days, cigarette smoking history in the last 30 days, and region were associated factors with khat chewing with a $p$-value $<0.2$. In the multivariable analysis Age, educational status, occupation, religion, wealth index, current marital status, alcohol drinking history in the last 30 days, cigarette smoking history in the last 30 days, and region were significantly associated with current khat chewing at a pvalue $<0.05$

The odds of khat chewing among older adults were higher than that of teenagers aged between 15 and 19 years. When compared to adults who had higher educational status those who had no education $(\mathrm{AOR}=1.62$, $95 \%$ CI: $1.10,2.39$ ) and primary education (AOR $=1.85$, 95\% CI: .30, 2.62) had higher odds of chewing khat. When compared to participants who have no job those with jobs have higher odds of Khat chewing. Muslim study participants had higher odds of chat chewing ( $\mathrm{AOR}=18.30,95 \% \mathrm{CI}: 13.54,24.74)$ when compared to Orthodox Christians whereas Catholics (AOR $=0.16$, 95\% CI: $0.05,0.48)$ and Protestants $(\mathrm{AOR}=0.20,95 \% \mathrm{CI}$ : $0.13,0.31$ ) had lower odds of khat chewing. Participants who have poorer wealth index had 33\% lower odds of Khat chewing $(\mathrm{AOR}=0.67,95 \% \mathrm{CI}: 0.51,0.89)$ when compared to the poorest. The odds of being current khat chewer among divorced men were reduced by $62 \%$ (AOR $=0.38,95 \%$ CI: $0.21,0.69)$ as compared to singles. Participants who drink alcohol in the last 30 days had $2.15(\mathrm{AOR}=2.15,95 \% \mathrm{CI}: 1.69,2.73)$ times higher odds of being current khat chewer than their counterparts likewise those who smoke cigarette in the last 30 days had $14.92(\mathrm{AOR}=14.92,95 \% \mathrm{CI}: 10.88,20.47)$ times higher odds of being current khat chewer than those who do not. The odds of khat chewing had also a significant difference among regions of Ethiopia (Table 3).

Table 2 Model comparison for identifying factors affecting khat chewing among male adults 15-59 years in Ethiopia, 2016

\begin{tabular}{ll}
\hline Model & Deviance \\
\hline Model I (Null Model) & 3869.58 \\
Model II (individual level factors) & 2944.39 \\
Model III (community-level factors) & 3745.34 \\
Model IV (both individual and community-level factors) & 2858.58 \\
\hline
\end{tabular}


Table 3 Multivariable logistic regression analysis among adult males in Ethiopia, 2016

\begin{tabular}{|c|c|c|c|c|c|}
\hline \multirow[t]{2}{*}{ Variable } & \multicolumn{2}{|c|}{ Khat chewing } & \multirow[t]{2}{*}{$\operatorname{COR}(95 \% \mathrm{Cl})$} & \multirow[t]{2}{*}{$\mathrm{AOR}(95 \% \mathrm{Cl})$} & \multirow[t]{2}{*}{$\mathrm{AOR}(95 \% \mathrm{Cl})$} \\
\hline & Yes & No & & & \\
\hline \multicolumn{6}{|l|}{ Individual-level factors } \\
\hline \multicolumn{6}{|l|}{ Age } \\
\hline $15-19$ & 331 & 2241 & 1.00 & 1.00 & 1.00 \\
\hline $20-24$ & 394 & 1486 & $3.0(2.35,3.83)$ & $2.66(2.00,3.52)$ & $2.68(2.02,3.56)^{*}$ \\
\hline $25-29$ & 577 & 1398 & $6.11(4.84,7.72)$ & $6.27(4.58,8.59)$ & $6.24(4.55,8.56)^{*}$ \\
\hline $30-34$ & 500 & 1114 & $6.72(5.26,8.57)$ & $6.74(4.75,9.56)$ & $6.59(4.64,9.36)^{*}$ \\
\hline $35-39$ & 375 & 996 & $5.77(4.43,7.51)$ & $5.19(3.56,7.57)$ & $4.92(3.37,7.18)^{*}$ \\
\hline $40-44$ & 317 & 871 & $5.94(4.57,7.73)$ & $5.05(3.45,7.42)$ & $4.99(3.40,7.34)^{*}$ \\
\hline $45-49$ & 222 & 711 & $4.01(2.98,5.39)$ & $2.91(1.92,4.39)$ & $2.89(1.91,4.37)^{*}$ \\
\hline $50-54$ & 141 & 434 & $4.60(3.25,6.49)$ & $3.91(2.45,6.24)$ & $3.81(2.38,6.10)^{*}$ \\
\hline $55-59$ & 116 & 371 & $4.49(3.15,6.40)$ & $4.74(2.94,7.65)$ & $4.66(2.89,7.57)^{*}$ \\
\hline \multicolumn{6}{|l|}{ Educational level } \\
\hline No education & 1078 & 2695 & $2.09(1.59,2.75)$ & $1.43(0.97,2.11)$ & $1.62(1.10,2.39)^{*}$ \\
\hline Primary education & 1419 & 4457 & $1.39(1.09,1.79)$ & $1.72(1.21,2.43)$ & $1.85(1.30,2.62)^{*}$ \\
\hline Secondary education & 302 & 1544 & $0.95(0.74,1.24)$ & $1.28(0.91,1.18)$ & $1.32(0.94,1.87)$ \\
\hline Higher education & 176 & 923 & 1.00 & 1.00 & 1.00 \\
\hline \multicolumn{6}{|l|}{ Occupation } \\
\hline Not working & 86 & 858 & 1.00 & 1.00 & 1.00 \\
\hline Professional/technical/managerial & 114 & 517 & $5.54(3.74,8.19)$ & $3.44(2.10,5.65)$ & $3.59(2.18,5.91)^{*}$ \\
\hline Clerical & 17 & 80 & $7.09(3.54,14.19)$ & $8.21(3.59,18.77)$ & $8.49(3.68,19.55)^{*}$ \\
\hline Sales & 152 & 525 & $5.20(3.55,7.60)$ & $2.47(1.58,3.86)$ & $2.53(1.61,3.97)^{*}$ \\
\hline Agriculture - employee & 2168 & 6168 & $4.66(3.43,6.34)$ & $2.50(1.74,3.59)$ & $2.57(1.78,3.72)^{*}$ \\
\hline Services & 48 & 162 & $6.17(3.68,10.33)$ & $3.23(1.74,5.98)$ & $3.16(1.70,5.89)^{*}$ \\
\hline Skilled manual & 205 & 619 & $9.92(6.88,14.32)$ & $5.48(3.57,8.40)$ & $5.68(3.68,8.76)^{*}$ \\
\hline Unskilled manual & 52 & 227 & $5.27(3.14,8.83)$ & $3.75(2.02,6.98)$ & $4.01(2.14,7.54)^{*}$ \\
\hline Others & 132 & 466 & $5.11(3.40,7.68)$ & $3.69(2.31,5.89)$ & $3.70(2.30,5.96)^{*}$ \\
\hline \multicolumn{6}{|l|}{ Religion } \\
\hline Orthodox & 325 & 5352 & 1.00 & 1.00 & 1.00 \\
\hline Catholic & 11 & 79 & $0.15(0.06,0.38)$ & $0.19(0.06,0.60)$ & $0.16(0.05,0.48)^{*}$ \\
\hline Protestant & 98 & 2648 & $0.13(0.09,0.19)$ & $0.26(0.17,0.40)$ & $0.2(0.13,0.31)^{*}$ \\
\hline Muslin & 2505 & 1411 & $8.78(7.04,10.94)$ & $21.59(16.00,9.19)$ & $18.30(13.54,4.74)^{*}$ \\
\hline Traditional+other & 37 & 129 & $0.50(0.06,0.09)$ & $0.60(0.20,1.85)$ & $0.43(0.14,1.31)$ \\
\hline \multicolumn{6}{|l|}{ Sex of household head } \\
\hline Male & 2658 & 8376 & $1.56(1.30,1.88)$ & $1.01(0.81,1.27)$ & $1.03(0.82,1.30)$ \\
\hline Female & 317 & 1244 & 1.00 & 1.00 & \\
\hline \multicolumn{6}{|l|}{ Wealth Index } \\
\hline Poorest & 621 & 1358 & 1.00 & 1.00 & 1.00 \\
\hline Poorer & 660 & 1634 & $0.64(0.50,0.81)$ & $0.71(0.54,0.93)$ & $0.67(0.51,0.89)^{*}$ \\
\hline Middle & 616 & 1811 & $0.69(0.54,0.88)$ & $0.84(0.63,1.12)$ & $0.80(0.60,1.08)$ \\
\hline Richer & 495 & 2217 & $0.56(0.43,0.72)$ & $0.81(0.60,1.10)$ & $0.76(0.56,1.03)$ \\
\hline Richest & 582 & 2600 & $0.74(0.55,1.00)$ & $1.18(0.83,1.68)$ & $0.94(0.63,1.39)$ \\
\hline \multicolumn{6}{|l|}{ Current marital status } \\
\hline Never in union & 854 & 4036 & 1.00 & 1.00 & 1.00 \\
\hline
\end{tabular}


Table 3 Multivariable logistic regression analysis among adult males in Ethiopia, 2016 (Continued)

\begin{tabular}{|c|c|c|c|c|c|}
\hline \multirow[t]{2}{*}{ Variable } & \multicolumn{2}{|c|}{ Khat chewing } & \multirow[t]{2}{*}{$\operatorname{COR}(95 \% \mathrm{Cl})$} & \multirow[t]{2}{*}{$\mathrm{AOR}(95 \% \mathrm{Cl})$} & \multirow[t]{2}{*}{$\mathrm{AOR}(95 \% \mathrm{Cl})$} \\
\hline & Yes & No & & & \\
\hline Married & 1814 & 5154 & $2.40(2.09,2.75)$ & $0.81(0.63,1.04)$ & $0.83(0.64,1.06)$ \\
\hline Living with partner & 245 & 176 & $2.98(1.89,4.70)$ & $1.44(0.83,2.50)$ & $1.27(0.74,2.19)$ \\
\hline Widowed & 12 & 32 & $4.69(1.75,12.58)$ & $1.20(0.36,4.020$ & $1.17(0.34,3.94)$ \\
\hline Divorced & 36 & 189 & $1.29(0.76,2.19)$ & $0.35(0.19,0.65)$ & $0.38(0.21,0.69)^{*}$ \\
\hline No longer living together/separated & 13 & 33 & $3.17(1.27,7.88)$ & $1.86(0.64,5.37)$ & $1.88(0.62,5.65)$ \\
\hline \multicolumn{6}{|l|}{ Alcohol drinking in the last 30 days } \\
\hline Yes & 478 & 4949 & $1.12(0.95,1.33)$ & $1.91(1.50,2.43)$ & $2.15(1.69,2.73)^{*}$ \\
\hline No & 2496 & 4671 & 1.00 & 1.00 & 1.00 \\
\hline \multicolumn{6}{|l|}{ Smoking cigarette in the last 30 days } \\
\hline Yes & 526 & 129 & $21.62(16.01,29.18)$ & $16.87(12.30,23.14)$ & $10.79(8.61,13.51)^{*}$ \\
\hline No & 2449 & 9491 & 1.00 & 1.00 & 1.00 \\
\hline \multicolumn{6}{|l|}{ Community-level factors } \\
\hline \multicolumn{6}{|l|}{ Residence } \\
\hline Urban & 482 & 2014 & $2.13(1.31,3.45)$ & $1.01(0.58,1.75)$ & $1.17(0.66,2.07)$ \\
\hline Rural & 2493 & 7606 & 1.00 & & \\
\hline \multicolumn{6}{|l|}{ Region } \\
\hline Oromia & 1875 & 2839 & 1.00 & 1.00 & 1.00 \\
\hline Tigray & 19 & 776 & $0.01(0.01,0.03)$ & $0.01(0.01,0.03)$ & $0.03(0.01,0.07)^{*}$ \\
\hline Afar & 28 & 54 & $0.93(0.35,2.45)$ & $0.93(0.35,2.45)$ & $0.28(0.11,0.68)^{*}$ \\
\hline Amhara & 304 & 2902 & $0.04(0.02,0.09)$ & $0.04(0.02,0.09)$ & $0.07(0.04,0.14)^{*}$ \\
\hline Somali & 142 & 184 & $1.60(0.76,3.39)$ & $1.60(0.76,3.39)$ & $0.36(0.18,0.70)^{*}$ \\
\hline Benishangul & 22 & 102 & $0.26(0.10,0.68)$ & $0.26(0.10,0.68)$ & $0.14(0.06,0.35)^{*}$ \\
\hline SNNPR & 392 & 2194 & $0.10(0.05,0.21)$ & $0.10(0.05,0.21)$ & $0.53(0.29,0.99)^{*}$ \\
\hline Gambella & 8 & 29 & $0.30(0.08,1.10)$ & $0.30(0.08,1.11)$ & $0.78(0.21,2.94)$ \\
\hline Harari & 23 & 8 & $11.04(3.11,39.16)$ & $10.99(3.02,40.00)$ & $6.97(1.91,25.43)^{*}$ \\
\hline Addis Ababa & 118 & 503 & $0.41(0.19,0.87)$ & $0.41(0.17,0.99)$ & $0.30(0.14,0.66)^{*}$ \\
\hline Dire Dawa & 45 & 27 & $4.65(1.74,12.37)$ & $4.62(1.64,13.02)$ & $2.77(1.05,7.30)^{*}$ \\
\hline
\end{tabular}

\section{Discussion}

The study determined the prevalence of current khat chewing status and factors affecting it among male adults of Ethiopia. A range of different sociodemographic and economic factors affecting current khat chewing was identified, these include Older age, being uneducated, Muslim religion follower, poorest wealth index, being divorce, history of alcohol drinking for the last 30 days, history of cigarette smoking for the last 1 month, and regions of Harari and Dire Dawa had statistically significant association with khat chewing.

Older people had higher odds of being a khat chewer as compared to teenagers. This finding is in line with other studies conducted in different institutions in Ethiopia [1,2] and a community-based study on EDHS 2011 [26]. The possible reason could be young people tend to be under family control which reduces their risk of exposure. As a result, their probability of chewing will be less.

Lower educational status was found to be a significant independent predictor of current khat chewing. This finding is in contrast with a study conducted in Butajira, Ethiopia [13]. But, the current study was in agreement with a study conducted from the Jazan region, Saudi Arabia, which showed that illiterates were at higher odds of chewing khat [23]. The reason could be uneducated men would have a lack of information on the negative consequences of khat on their health [27]. Therefore, they would continue khat chewing.

The type of occupation was associated with khat chewing. Accordingly, professionals, clerical, sales, agricultural, service, skilled manual, and unskilled manual workers were at higher odds of being khat chewer. This 
finding is in line with a study conducted in Ethiopia [26]. This could be due to the fact that jobless individuals cannot afford to buy khat and also they have relatively less work which will stress them so as to need such stimulants.

In this study, Muslims were at higher risk of being khat chewer when compared to Orthodox Christians whereas being Catholic and Protestant was found to decrease the odds of chewing khat. This finding is in line with other studies from Ethiopia [1, 12, 13, 28]. This could be traditionally Muslim religious followers have good acceptance to gain maximum concentration while doing their work and prayer [27, 29].

The odds of khat chewing among poor people were reduced by $33 \%$ compared to those with the poorest wealth index. This finding is in agreement with a community-based study from EDHS 2011 [26]. This could be because the poorest people could not even afford basic necessities like food and unable to cover the expense of khat [30].

Divorced men were associated with lower odds of Khat chewing than their single counterparts. This finding is in contrast with a study conducted in Ethiopia [26]. The lower odds of khat chewing among divorced people could be their tendency to modify their lifestyle after divorce as this khat chewing could be also a reason for the divorce. Single individuals usually are also young people who are under family control.

In this study, alcohol drinking is associated with an increased risk of khat chewing as compared to their counterparts. This result is consistent with a systematic review and meta-analysis [31]. A similar association was found from the study conducted in Butajira [13], Saudi Arabia [6], and Uganda [32]. This could be due to the fact that khat chewing causes sleep disturbance [33] as a result, chewers would use alcohol for better sleep. However, different studies showed concurrent use of khat, cigarette, and alcohol would result in sleep deprivation [32, 34, 35]. Therefore, giving due attention is needed to minimize the concurrent effect of khat, alcohol, and cigarette smoking.

Community-level factors of khat chewing were also determined and the region was significantly associated with khat chewing. Men living in the regions of Harari and Dire Dawa were at higher odds of khat chewing. This finding is in line with a study conducted in Ethiopia [26]. This due to the cultural difference across the regions and especially khat chewing in the Eastern part of Ethiopia is culturally acceptable and is considered as a good practice.

This study has a significant implication for the public and policymakers. Khat chewing in the community could affect social life [24], the economy [27], and result in poor health outcomes [35-38]. Currently, in Ethiopia farmers in the rural area are expanding the cultivation of khat and the landmass covered by cereals and fruits is decreasing from time to time. However, the negative effect of khat on health outweighs the income earned from khat production and sale. In addition, khat chewers are prone to poor appetite and resulted in malnutrition. Khat chewing is also a growing concern among Ethiopian universities [39] associated with low academic performance in Ethiopian students [40-42]. Khat chewing contributes to the high burden of non-communicable diseases like cardiovascular disorders [43, 44]. Khat increases the concurrent use of cigarettes and increases risky sexual behavior [9] which further increases the burden of the Human Immune Deficiency Virus (HIV). Khat mainly affects the productive population of a country like university students, youths, and employers this will affect the country's economy at large in the long run. Therefore, policymakers should design strategies on khat sale and production including high taxation or banning to minimize the burden.

\section{Limitations}

Since the study was cross-sectional it does not show the temporal relationship between the outcome status and the risk factors. Important variables like peer pressure and perceptions/attitude on benefit, consequence, duration of chewing, dosage and frequency were not addressed in this study. So, the long term implications of khat were not studied in this study. However, the authors tried to determine the causes of khat chewing in Ethiopia among the men population.

\section{Conclusion}

Older age, being uneducated, Muslim religion follower, poorest wealth index, being divorce, history of alcohol drinking for the last 30 days, history of cigarette smoking for the last 1 month, and regions of Harari and Dire Dawa had a statistically significant association with khat chewing. Therefore, to effectively control khat chewing among the diverse communities in Ethiopia, policymakers should consider a multi-faceted policy approach that accounts for regional variation, the local social contexts, as well as the complementary nature of smoking and khat chewing practices.

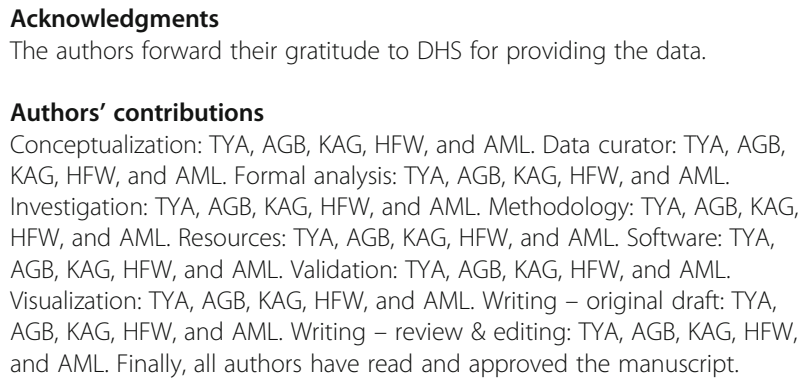




\section{Availability of data and materials}

Data is available on https://dhsprogram.com/data/available-datasets.cfm

\section{Ethics approval and consent to participate}

Permission to use the EDHS data was obtained from the Measure DHS international program. The data is publicly available and has no personal identifiers.

\section{Consent for publication}

Not applicable.

\section{Competing interests}

The authors declare that they have no competing interests.

\section{Author details}

${ }^{1}$ Department of Epidemiology and Biostatistics, Institute of Public Health, College of Medicine and Health Sciences, University of Gondar, Gondar, Ethiopia. ${ }^{2}$ Department of Human Nutrition, Institute of Public Health, College of Medicine and Health Sciences, University of Gondar, Gondar, Ethiopia.

Received: 12 July 2019 Accepted: 8 January 2020

Published online: 14 January 2020

\section{References}

1. Reda AA, et al. Prevalence and determinants of khat (Catha edulis) chewing among high school students in eastern Ethiopia: a cross-sectional study. PLoS One. 2012;7(3):e33946.

2. Dires $\mathrm{E}_{\text {, et }}$ al. Factors associated with khat chewing among high school students in Jimma town Southwest Ethiopia. J Psychiatry. 2016;19(4):372

3. Teni F, et al. Prevalence, reasons, and perceived effects of khat chewing among students of a college in Gondar town, northwestern Ethiopia: a cross-sectional study. Ann Med Health Sci Res. 2015;5(6):454-60.

4. Wendy Sykes, et al., Perceptions of the social harms associated with khat use. Home office, 2010.

5. Mulugeta Y. Khat chewing and its associated factor among college students in Bahir Dar town, Ethiopia. Sci J Public Health. 2013;1(5):209-14.

6. Alsanosy RM, Mahfouz MS, Gaffar AM. Khat chewing among students of higher education in Jazan region, Saudi Arabia: prevalence, pattern, and related factors. Biomed Res Int. 2013;2013:1-7.

7. Balint EE, Falkay G, Balint GA. Khat-a controversial plant. Wien Klin Wochenschr. 2009;121(19-20):604.

8. Woldeamanuel GG, Geta TG. Impact of chronic khat (Catha edulis Forsk) chewing on pulmonary function test and oxygen saturation in humans: a comparative study. SAGE Open Med. 2019;7:2050312118824616.

9. Abate $A$, et al. Chewing khat and risky sexual behavior among residents of Bahir Dar City administration, Northwest Ethiopia. Ann Gen Psychiatry. 2018;17:26.

10. Ware $E$, et al. Disparities in risky sexual behavior among khat chewer and non- chewer college students in southern Ethiopia: a comparative crosssectional study. BMC Public Health. 2018;18(1):558.

11. Adorjan $\mathrm{K}$, et al. Khat use and occurrence of psychotic symptoms in the general male population in southwestern Ethiopia: evidence for sensitization by traumatic experiences. World Psychiatry. 2017;16(3):323.

12. Manzar MD, et al. Poor sleep in concurrent users of alcohol, khat, and tobacco smoking in community-dwelling Ethiopian adults. Ann Thorac Med. 2018;13(4):220-5.

13. Alem A, Kebede D, Kullgren G. The prevalence and socio-demographic correlates of khat chewing in Butajira, Ethiopia. Acta Psychiatrica Scandinavica. 1999;100:84-91.

14. Sinshaw AE. Prevalence and associated factors of khat chewing among Atse Fasil campus student in University of Gondar, North West Ethiopia. Malays J Med Biol Res. 2014;1(2):53-64.

15. Wazema DH, Madhavi K. Prevalence of Khat abuse and associated factors among undergraduate students of Jimma University, Ethiopia. Int J Res Med Sci. 2017;3(7):1751-7.

16. Gelaw Y, Haile-Amlak A. Khat chewing and its socio-demographic correlates among the staff of Jimma University. Ethiop J Health Dev. 2004;18(3):179-84.

17. Ethiopian Demographic and Health Survey 2016. Central statistical agency Addis Ababa, Ethiopia The DHS Program ICF Rockville, Maryland, USA, 2017.

18. Reda AA, Moges A, Biadgilign S, Wondmagegn BY. Prevalence and determinants of khat (Catha edulis) chewing among high school students in eastern Ethiopia: a cross-sectional study. PLoS one. 2012;7(3):e33946.
19. Lakew A, et al. Prevalence of catha edulis (khat) chewing and its associated factors among ataye secondary school students in northern shoa, Ethiopia. Adv Appl Sociol. 2014;4(10):225.

20. Deribachew Hailemariam Wazema and Kanchi. Madhavi, Prevalence of Khat abuse and associated factors among undergraduate students of Jimma University, Ethiopia. Int J Res Med Sci https://doi.org/10.18203/2320-6012. ijrms20150264, 2015. 3(7): p. 1751-1757.

21. Jima SB, Tefera TB, Ahmed MB. Prevalence of tobacco consumption, alcohol, Khat (Catha Edulis) use and high blood pressure among adults in Jimma town, South West Ethiopia. Science. 2015;3(5):650-4.

22. Dachew BA, Bifftu BB, Tiruneh BT. Khat use and its determinants among university students in Northwest Ethiopia: a multivariable analysis. Int J Med Sci Public Health. 2015;4(3):319-23.

23. Alsanosy RM, Mahfouz MS, Gaffar AM. Khat chewing habit among school students of Jazan region, Saudi Arabia. Plos one. 2013;8(6):e65504.

24. Sykes $W$, et al. Perceptions of the social harms associated with khat use. Home Office Online Report. London: Home Office; 2010.

25. Diez-Roux AV. Multilevel analysis in public health research. Annu Rev Public Health. 2000;21(1):171-92.

26. Haile D, Lakew $Y$. Khat chewing practice and associated factors among adults in Ethiopia: further analysis using the 2011 demographic and health survey. PLoS One. 2015;10(6):e0130460.

27. Aden $\mathrm{A}$, et al. Socio-economic effects of khat chewing in north eastern Kenya. East Afr Med J. 2006;83(3):69-73.

28. Ethiopia Demographic and Health Survey. 2011 central statistical agency Addis Ababa. Maryland: Ethiopia ICF International Calverton; 2012.

29. Zeleke A, Awoke W, Gebeyehu E, Ambaw F. Khat chewing practice and its perceived health effects among communities of Dera Woreda, Amhara region, Ethiopia. Open J Epidemiol. 2013;3:160-8.

30. Andualem M. The prevalence and socio- demo-graphic characteristics of khat chewing in Jimma town, South Western Ethiopia. Ethiopian J Health Sci. 2002;12:69-80.

31. Gebrie A, et al. Prevalence and predictors of khat chewing among Ethiopian university students: a systematic review and meta-analysis. PLoS One. 2018; 13(4):e0195718

32. Ihunwo AO, Kayanja Fl, Amadi-Ihunwo UB. Use and perception of the psychostimulant, khat (catha edulis) among three occupational groups in south western Uganda. East Afr Med J. 2004;81(9):468-73.

33. Wabe NT. Chemistry, pharmacology, and toxicology of khat (catha edulis forsk): a review. Addict Health. 2011;3(3-4):137-49.

34. Nakajima M, et al. Habitual khat and concurrent khat and tobacco use are associated with subjective sleep quality. Prev Chronic Dis. 2014;11:E86.

35. Manzar MD, et al. Psychometric properties of the Insomnia Severity Index in Ethiopian adults with substance use problems. J Ethn Subst Abus. 2018:1-15.

36. Odenwald, M. and M. al'Absi, Khat use and related addiction, mental health and physical disorders: the need to address a growing risk. East Mediterr Health J, 2017. 23(3): p. 236-244.

37. Mihretu A, Teferra S, Fekadu A. What constitutes problematic khat use? An exploratory mixed methods study in Ethiopia. Subst Abuse Treat Prev Policy. 2017;12(1):17.

38. Hassan NA, Gunaid AA, Murray-Lyon IM. Khat (Catha edulis): health aspects of khat chewing. East Mediterr Health J. 2007;13(3):706-18.

39. Gebrehanna E, Berhane Y, Worku A. Khat chewing among Ethiopian University Students--a growing concern. BMC Public Health. 2014;14:1198.

40. Kassa A, Loha E, Esaiyas A. Prevalence of khat chewing and its effect on academic performance in Sidama zone, Southern Ethiopia. Afr Health Sci. 2017;17(1):175-85.

41. Mekonen T, et al. Substance Use as a Strong Predictor of Poor Academic Achievement among University Students. Psychiatry J. 2017;2017:7517450.

42. Al-Sanosy RM. Pattern of khat abuse and academic performance among secondary school and college students in jazan region, Kingdom of Saudi Arabia (ksa). J Family Community Med. 2009;16(3):89-95.

43. Ahmed SH, et al. The prevalence of selected risk factors for noncommunicable diseases in Hargeisa, Somaliland: a cross-sectional study. BMC Public Health. 2019;19(1):878.

44. Ageely HM. Health and socio-economic hazards associated with khat consumption. J Family Community Med. 2008;15(1):3-11.

\section{Publisher's Note}

Springer Nature remains neutral with regard to jurisdictional claims in published maps and institutional affiliations. 